\title{
Attitude of cancer patients from online self-help groups towards physical activity
}

\author{
Imke Roth $^{1} \cdot$ Clara Dubois $^{1} \cdot$ Thorsten Schmidt $^{2}$ · Jutta Hübner ${ }^{1}$
}

Received: 11 February 2020 / Accepted: 17 March 2020 / Published online: 26 March 2020

(c) The Author(s) 2020

\begin{abstract}
Purpose Physical activity (PA) is important for cancer patients during and after therapy with respect to reducing side effects and improving quality of life. The aim of the study was to examine how physically active German cancer patients are and to identify predictors for PA. In addition, patients were asked about their attitude towards PA.

Methods A questionnaire was passed on to members of self-help groups. Multiple regression analyses were run to examine possible predictors such as self-efficacy, patient activation, gender, previous PA, therapy status, and age for PA.

Results $62 \%$ of the participants followed the official recommendations by the American Cancer Society for weekly aerobic activity. Multiple regression analyses could confirm age as a predictor for total PA. Higher self-efficacy and patient activation were associated with lower disease burden and a more positive attitude towards PA.

Conclusion This study contributes to the minor knowledge about PA among cancer patients. The examined group showed that there is potential for improvement regarding PA, although the majority had a positive attitude towards PA. Because of the small sample size existing of online self-help group members, results should be taken with caution.
\end{abstract}

Keywords Physical activity $\cdot$ Cancer $\cdot$ Self-efficacy $\cdot$ Patient activation $\cdot$ Predictors

\section{Introduction}

\section{Physical activity}

Physical activity (PA) plays an important role in cancer therapy for primary and relapse prevention. Furthermore, PA can have positive effects in every therapy phase. It can improve physical functioning and reduce therapy-related side effects such as fatigue (Hayes et al. 2013; McNeely et al. 2006). Furthermore, increased post-surgery PA is associated with better recovery (van Zutphen et al. 2017). In contrast, inactivity can weaken the skeleton and can lead to muscle loss as well as overweight. Being physically active has a significant association with health-related quality of life (Blanchard et al. 2008; Ferrer et al. 2011; McNeely et al. 2006). In

Jutta Hübner

jutta.huebner@med.uni-jena.de

1 Klinik für Innere Medizin, Universitätsklinikum Jena, Am Klinikum 1, 07747 Jena, Germany

2 Krebszentrum Nord, CCC, Universitätsklinikum Schleswig-Holstein, Campus Kiel, Arnold-Heller-Straße 3, Haus 14, 24105 Kiel, Germany addition, a meta-analysis by Schmid and Leitzmann showed that post-diagnosis PA is associated with a reduced risk of total mortality among breast and colorectal cancer patients, especially when patients engage in moderate activity of at least 150 min a week (Schmid and Leitzmann 2014). Similar results could also be found in patients with prostate cancer (Friedenreich et al. 2016; Kenfield et al. 2011). Another study including three different cohorts of breast cancer survivors found that low post-diagnosis PA increases all-cause mortality and breast cancer-related mortality (Nelson et al. 2016). Furthermore, PA can help to prevent the development of common comorbidities such as cardiovascular diseases (Lear et al. 2017) by decreasing insulin levels, reducing adiposity and decreasing the level of sex hormones and inflammation markers (McTiernan 2008). The risk-reducing effect does not depend on the type of PA but on the duration and intensity of the activity. A guideline for nutrition and PA from the American Cancer Society suggests $150 \mathrm{~min}$ of moderate or $75 \mathrm{~min}$ of vigorous weekly aerobic PA for cancer patients (Rock et al. 2012). An observational study among US cancer survivors found that only $12.6 \%$ of the cancer survivors were sufficiently active, respectively, meeting the guideline criteria and that older, female and obese 
cancer survivors were the least physically active (Loprinzi et al. 2013a). Furthermore, a few studies concerning breast cancer patients proclaim that PA levels decrease after diagnosis and do not return to the pre-diagnosis level (Devoogdt et al. 2010; Irwin et al. 2003). To our knowledge, German studies on PA in cancer patients are rare. A study by Höh et al. reported that the majority ( $68 \%$ ) of examined cancer patients were physically active at least 3 days a week (Hoh et al. 2017). However, in the study patients were only asked how many times a week, they engaged in some kind of physically straining activity. The actual intensity of the activities was not measured.

\section{Patient activation and self-efficacy}

A potential predictor of PA might be patient activation. Patient activation describes a patient's engagement in health care. Patients show various ways to deal with their disease. They differ in individual skills, confidence, and knowledge in managing their own health. Some are relatively passive; others have confidence and knowledge to self-manage their health behaviors. To participate actively in one's own medical care is essential for effective management of chronic diseases, e.g., cancer, and is essential for good compliance. Moreover, better health status and outcome are reported for patients with high patient activation (Jessica Greene et al. 2015). Cancer patients with high patient activation are more likely to eat a healthier diet, to deal with side effects efficiently and to be satisfied with their treatment by feeling better informed and understanding their diagnosis (Hibbard et al. 2017). In addition, a study by Hibbard et al. showed that positive changes in patient activation of patients with chronic disease were positively related to self-managed health behaviors such as regular exercise (Hibbard et al. 2007). Self-efficacy developed by Bandura (1994) is another concept that could possibly affect PA in cancer patients. Bauman et al. reported self-efficacy as a determinant for PA in a healthy population (Bauman et al. 2012). Self-efficacy represents the general ability to deal with difficult challenges and the level of confidence in being able to solve problems autonomously. It is a personal characteristic that might help to overcome barriers regarding PA and increase PA. A cancer diagnosis is a life-changing event and is often perceived as an extreme burden. This burden might be decreased by better self-efficacy and patient activation, since both characteristics are negatively correlated with depression (Ding et al. 2017; Goodworth et al. 2014).

\section{Attitude towards PA}

Referring to a qualitative study examining cancer patients' views about PA, most participants are aware that PA has benefits relating to cancer and is good for general health.
Furthermore, most have the desire to increase their PA (Smith et al. 2017). Potentially, there might be a relation between the attitude towards PA and performed PA. Höh et al. reported that being rarely physically active was associated with uncertainty about the positive effects of PA such as increased well-being or better coping with the disease (Hoh et al. 2017).

\section{Aim}

The aim of this study was to evaluate how physical active German cancer patients are and to identify relevant determinants of PA such as self-efficacy and patient activation. Furthermore, the goal was to explore cancer patients' attitudes towards PA and their satisfaction with their performed PA. With these data, more effective interventions may be developed and target groups for sport interventions may be defined in more detail.

\section{Methods}

\section{Study design, participants and material}

The survey was conducted over a period of 5 months from March to the middle of August 2018. The online questionnaire was passed on via email to members of the following self-help groups with online services: "Hautkrebs-Netzwerk Deutschland e.V." (English: Skin cancer network Germany) and "Das Lebenshaus e.V." (English: House of life). Furthermore, the link to the online questionnaire was shared via Facebook with group members of "Unterstützung bei Krebs" (English: Cancer Support). The objective of the survey was clearly stated and the participants were informed that participation was voluntary and anonymous. For Demographics see Table 1.

\section{Questionnaire}

The questionnaire consisted of demographic data (gender, age, therapy status, cancer type) and five additional sections:

\section{Level of PA}

PA was measured using the IPAQ long-form (International Physical Activity Questionnaire). The IPAQ has been developed to measure PA in adults age 15-69 and has acceptable measurement properties with a reliability of 0.80 and validity of 0.30 (Craig et al. 2003). The IPAQ was evaluated using the Guidelines for Data Processing and Analysis (Committee IR 2005). The IPAQ collects information about the duration, frequency and intensity of PA in four domains: (1) work, (2) transport, (3) domestic and gardening, and (4) leisure time 
Table 1 Demographics

\begin{tabular}{|c|c|c|}
\hline & Total & in $\%$ \\
\hline \multicolumn{3}{|l|}{ Gender } \\
\hline Female & 115 & 89.1 \\
\hline Male & 14 & 10.9 \\
\hline \multicolumn{3}{|c|}{ Age (median 50 mean 48.6) } \\
\hline$<40(27-39)$ & 21 & 16.3 \\
\hline $40-49$ & 42 & 32.6 \\
\hline $50-59$ & 57 & 44.2 \\
\hline$>60$ & 9 & 7.0 \\
\hline \multicolumn{3}{|l|}{ Category } \\
\hline Patient under treatment & 57 & 44.2 \\
\hline Patient post treatment & 72 & 55.8 \\
\hline Patient in employment & 68 & 52.7 \\
\hline Patient unemployed & 61 & 47.3 \\
\hline \multicolumn{3}{|l|}{ Cancer type } \\
\hline Breast & 42 & 32.6 \\
\hline Malignant melanoma & 38 & 29.5 \\
\hline Sarcoma $^{\mathrm{a}}$ & 15 & 11.6 \\
\hline Gynaecological $^{\mathrm{b}}$ & 8 & 6.2 \\
\hline Gastrointestinal $^{c}$ & 4 & 3.1 \\
\hline Others $^{\mathrm{d}}$ & 22 & 17.1 \\
\hline
\end{tabular}

${ }^{\text {a Including GIST }}$

${ }^{\mathrm{b}}$ Ovarian-, cervix- cancer

${ }^{\mathrm{c}}$ Rectal-, stomach-, colon- cancer

${ }^{\mathrm{d}}$ Others $=$ thyroid-, lung-, bladder-cancer, NHL, glioblastoma, basal cell-, squamous cell-, renal cell carcinoma, solitary fibrous tumor, histiocytoma

during the last 7 days. A PA was only included if it was conducted a minimum duration of $10 \mathrm{~min}$. Metabolic equivalent task (MET)—minutes are calculated by multiplying durations, frequencies and MET scores for each type of activity. They combine duration and physical strain in a consistent and comparable measurement unit.

\section{Attitude towards PA}

The attitude was assessed with 12 statements on a 3-point scale such as "PA improves my body awareness." or "Since I felt ill every physical effort is too much for me.", to see whether the participants had a positive association towards PA (wellbeing, better coping, reducing cancer risk) or a rather negative association (harm, barriers) and if they were satisfied with their personal PA behavior.

\section{Self-efficacy}

To measure self-efficacy the ASKU (Allgemeine Selbstwirksamkeit Kurzskala-English: general self-efficacy short scale) developed by Beierlein et al. was used (Constanze
Beierlein 2012). It consists of three items on a 5-point Likert scale. The mean over all three items is calculated, ranging from 1 to 5. The internal validity of the ASKU is reported as high (Cronbach's $\alpha$ : 0.81-0.86) (Constanze Beierlein 2012). In this survey, the internal consistency was retested resulting in a similar value of $\alpha: 0.84$.

\section{Patient activation}

Patient activation was quantified using the PAM-13 (Patient activation measure 13). The questionnaire developed by Hibbard et al. consists of 13 items on a 4-point Likert scale. Following the manual, a sum score was calculated and transformed to a $0-100$ ranged scale. The patient activation can be categorized into four stages: (1) not believing the patient role is important $(\leq 47.0)$, (2) lack of confidence and knowledge necessary to take action (47.1-55.1), (3) beginning to take action to maintain and improve one's health (55.2-72.4) and (4) taking action ( $\geq 72.5$ ) (Jessica Greene et al. 2015). Internal consistency was tested with a good result of Cronbach's $\alpha=0.82$. This result is similar to the reported Cronbach's $\alpha$ of 0.84 for a German sample by Brenk-Franz et al. (2013).

\section{Disease burden}

At last, the participants were asked about how strongly they feel burdened by the disease and its consequences using a rating scale from 0 (not at all burdened) to 10 (extremely burdened).

\section{Statistics}

IBM SPSS Statistics 25 was used for data analysis. Two multiple linear regressions were calculated to test if self-efficacy, patient activation, age, therapy status, gender and previous PA could predict variables total PA over all domains and PA during leisure time. Since data were ordinal or significantly proved to be non-normal Spearman correlations were used to analyze relations between attitudes towards PA, patient activation, self-efficacy, disease burden and PA. $p$ values $<0.05$ were considered significant.

\section{Results}

\section{Demographics}

Among the analyzed sample $(n=129)$, the median age was 50 years and $89.1 \%$ were female. The most common cancer types were breast cancer $(32.6 \%)$ and malignant melanoma $(29.5 \%)$. For more information on demographics, see Table 1. 


\section{Physical activity}

$62 \%$ (80) of the participants followed the official recommendations by the American Cancer Society or the WHO for weekly aerobic activity which is represented by PA in leisure time ( $\geq 600$ MET-min/week). $68.1 \%$ of participants who had finished therapy met the criteria compared to $54.4 \%$ of the patients who were currently receiving therapy. Additionally, $48.1 \%$ even met the criteria for additional health benefits in leisure time, which means they engaged in $300 \mathrm{~min}$ or more of an equivalent on moderate activity. The mean MET-min/week was 7937.21 MET-min/week $(\mathrm{Mdn}=6492, \mathrm{SD}=5340.8), 50 \%$ had MET values between 3996 and 11828 MET-min/week. Values of MET-min/ week were rather positive skewed than normally distributed $($ skew $=0.754$; kurtosis $=-0.058)$. It appears that the greatest amount by $36 \%$ of the weekly activity is the result of activities in the domestic and gardening domain followed by work (23\%), leisure time (22\%) and transport (19\%). For average MET values, see Fig. 1. The median activity time per day was $220 \mathrm{~min}(M=265.30, \mathrm{SD}=176.01) .83 .7 \%$ were physically active in their leisure time, more than half joined different activities than just walking and $89.01 \%$ used walking or bike riding as a transport possibility.

\section{Patient activation, self-efficacy, disease burden}

The mean patient activation was $71.02(\mathrm{Mdn}=72.37$, $\mathrm{SD}=17.84)$. More than half of the patients $(58.1 \%, n=75)$ could be categorized into the highest category of patient activation, meaning that they were actively taking part in their own disease management. $20.9 \%$ were beginning to take action and $10.9 \%$ were categorized into "a lack of knowledge and confidence to take action". Only $10.1 \%$ were classified as hardly active meaning they did not believe their own role was important. The mean for self-efficacy was 3.71 $(\mathrm{Mdn}=4, \mathrm{SD}=0.75)$. The average perceived disease burden on a scale from 0 to 10 was $6.21(\mathrm{Mdn}=6, \mathrm{SD}=2.19)$. Patient activation $\left(r_{\mathrm{s}}=-0.27, p<0.01\right)$ and self-efficacy $\left(r_{\mathrm{s}}=-0.34, p<0.01\right)$ were both significantly correlated with disease burden.

\section{Attitude towards PA}

Almost $90 \%$ of the tumor patients agreed at least partially that PA improves their body awareness, their wellbeing and gave them a feeling they could do something to better cope with the disease. More than $80 \%$ were totally or partially convinced, that PA could help to reduce their risk for another tumor disease or the risk of tumor recurrence. 7.8\% were worried PA could harm them. Around 20\% stated they could hardly motivate themselves to be physically active. Less than 20\% said they never engaged in a lot of PA and did not find a good possibility to start. $79.1 \%$ were at least partially physically active before their disease. $23.4 \%$ were
Fig. 1 Mean MET-min/week divided by domains for therapy status, work status, age groups and gender
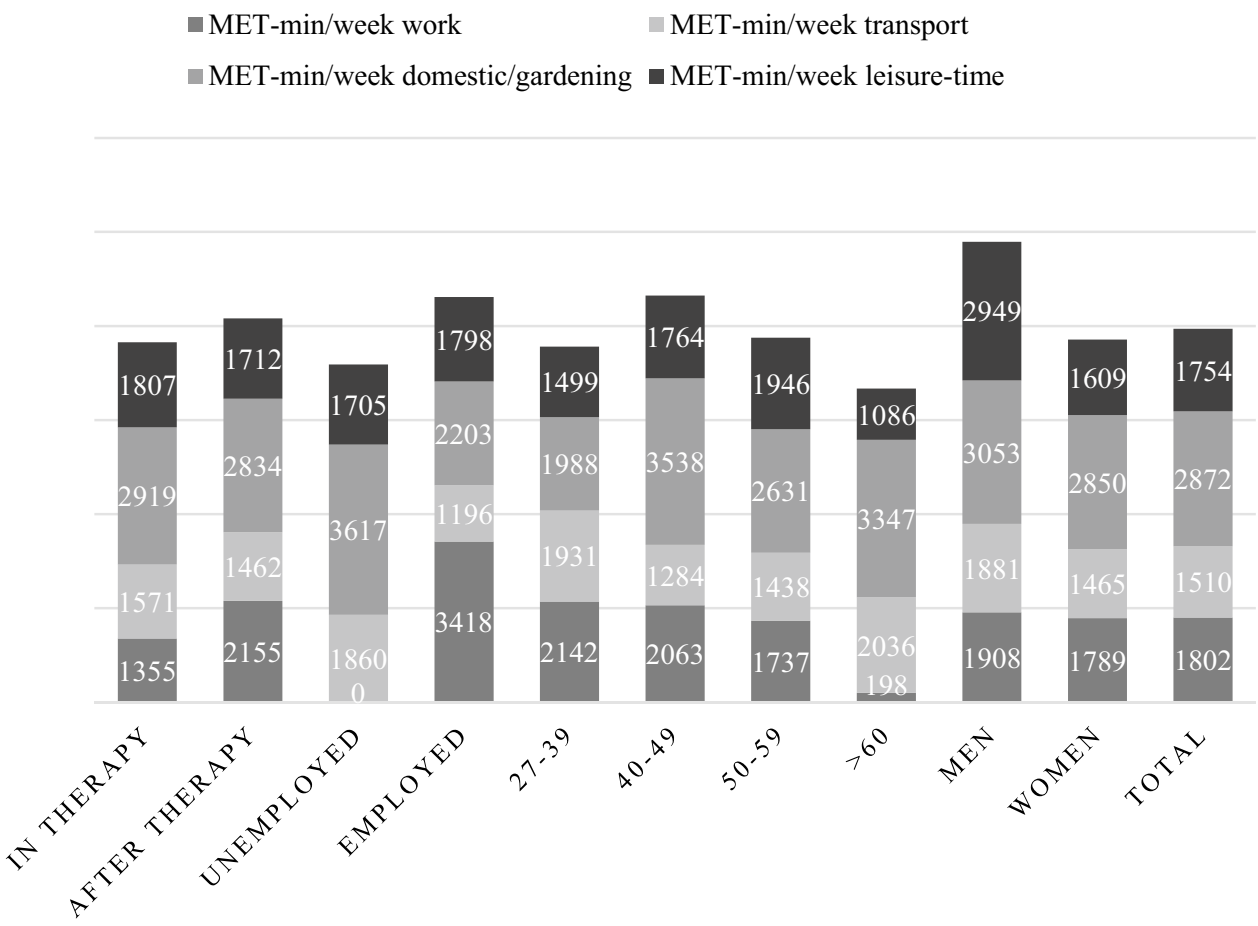
completely convinced to perform enough PA, whereas $84.5 \%$ wished to increase their level of activity.

People with a positive attitude towards PA had average higher total MET values than those with a rather negative attitude, but those differences were not statistically significant. Patients with good patient activation and high self-efficacy were significantly more likely to agree with statements emphasizing a positive attitude towards PA (Statement 1, 2, $3,4,11)$ and disagreed with those statements regarding a rather negative attitude (Statement 5, 6, 7, 8, 9), see Table 2 for $p$ values.

\section{Age as a predictor for PA}

Two multiple regression analyses were performed to assess the influence of gender, age, self-efficacy, patient activation, previous PA, and therapy status on total PA and on leisuretime PA (MET-min/week). All predictors were analyzed for multicollinearity and autocorrelation: The variance inflation factor (VIF) ranged between 1.05 and 1.25. Durbin-Watson was close to two (2.12) indicating that multicollinearity and autocorrelation were no issues. The first model for total PA was significant with $F(6,122), p=0.037$ and $R^{2}=0.103$ meaning the determinants included in the model accounted for approximately $10 \%$ of the variance of PA. This can be rated as a low attribute towards explained variance. Only age was a significant predictor with $=-0.19, p=0.033$. The second model assessing the same predictors for PA in leisure time did not become significant $(F(6,122), p=0.101$ and $R^{2}=0.082$ ). See Table 3 .

\section{Discussion}

\section{Most participants met the recommendation for PA}

The participating patients showed a very high PA in comparison to many other surveys. In the present study, $62 \%$ met the recommendation for aerobic PA which is represented by PA in leisure time. In contrast, a study on adherence to lifestyle behavior recommendations by Blanchard et al. found that only $29.6-47.3 \%$ met the PA recommendations. Skin cancer patients were closest to meeting the recommendations (47.3\%) (Blanchard et al. 2008). The high levels of PA in this study might be affected by $29.5 \%$ of participants

Table 2 Spearman Rho correlations $\left(r_{\mathrm{s}}\right)$ for statements towards PA with patient activation, self-efficacy and PA (total MET-min/week)

\begin{tabular}{|c|c|c|c|}
\hline Statement & Patient activation & Self-efficacy & PA \\
\hline 1. PA improves my body awareness. & $0.310 * *$ & $0.192 *$ & 0.126 \\
\hline 2. PA gives me the feeling that I can do something myself to better cope with the disease. & $0.415^{* *}$ & $0.235^{* *}$ & 0.162 \\
\hline 3. With PA I feel better. & $0.285 * *$ & $0.282 * *$ & 0.130 \\
\hline 4. PA can help me to reduce the risk for another tumor disease/the risk of tumor recurrence. & $0.398 * *$ & 0.020 & 0.153 \\
\hline 11. I think I perform enough PA. & $0.301 * *$ & $0.239 * *$ & $0.326^{* *}$ \\
\hline 5. Through PA I feel exhausted. & $-0.229 * *$ & $-0.216^{*}$ & -0.070 \\
\hline 6. I am afraid that PA harms me. & $-0.310 * *$ & $-0.258 * *$ & -0.167 \\
\hline 7. I can badly overcome to be physically active. & $-0.243 * *$ & $-0.263 * *$ & -0.130 \\
\hline 8. Since I felt ill every physical effort is too much for me. & $-0.365 * *$ & $-0.344 * *$ & -0.118 \\
\hline 9. I never engaged in a lot of PA and now I don't find a good possibility to start with. & $-0.208^{*}$ & $-0.221 *$ & -0.079 \\
\hline
\end{tabular}

$* * p<0.01, * p<0.05$

Table 3 Multiple regression model 1: total PA and model 2: leisure time PA

\begin{tabular}{|c|c|c|c|c|c|c|c|c|}
\hline & \multicolumn{4}{|l|}{ Total PA } & \multicolumn{4}{|c|}{ Leisure-time PA } \\
\hline & $B$ & SE $B$ & $\beta$ (Beta) & $p$ & $B$ & SE $B$ & $\beta$ (Beta) & $p$ \\
\hline Constant & 7938.93 & 4290.47 & & 0.067 & 1636.21 & 1672.37 & & 0.330 \\
\hline Self-efficacy & 648.80 & 677.16 & 0.09 & 0.340 & 317.78 & 263.95 & 0.12 & 0.231 \\
\hline Patient activation & 47.78 & 28.71 & 0.16 & 0.099 & 6.68 & 11.19 & 0.06 & 0.552 \\
\hline Gender & -2468.47 & 1533.14 & -0.14 & 0.110 & -1298.73 & 597.60 & -0.20 & 0.032 \\
\hline Therapy status & 1119.54 & 939.77 & 0.10 & 0.236 & 82.28 & 366.31 & 0.02 & 0.823 \\
\hline Previous PA & 698.36 & 608.08 & 0.10 & 0.253 & 269.04 & 237.02 & 0.10 & 0.259 \\
\hline Age & -118.98 & 55.11 & $-0.19 *$ & $0.033^{*}$ & -21.04 & 21.48 & -0.09 & 0.329 \\
\hline
\end{tabular}

Model 1: $R=0.321 R^{2}=0.103 F(6,122)=2.329 p<0.05$, model $2: R=0.287 R^{2}=0.082 F(6,122)=1.82 p=0.101$ 
with skin cancer. Another study that measured PA by accelerometer reported that only $12.6 \%$ of an American cancer population were sufficiently active (Loprinzi et al. 2013b). Yet another study found that $95.5 \%$ of patients with a cancer history did not meet the activity guidelines (Smith et al. 2011). To our knowledge, this study is the first providing detailed information on PA in German cancer populations. In comparison to the general German population patients in this survey showed higher PA. The health report by the DKV 2018 stated that only $43 \%$ of German citizens reached the benchmark for recommended PA (Froböse and WallmannSperlich 2018). However, studies using the IPAQ to measure PA reported similar results as in this study (Gerovasili et al. 2015; Lear et al. 2017).

However, it seems that we examined a relatively homogeneous highly active population. Most participants were very active, including some extreme cases and only very few patients with low levels. A reason for bias might be that the IPAQ is relatively long and asks for PA in different domains retrospectively which can lead to confusion and overreporting. Furthermore, the patients showed an overall positive attitude towards PA. Kwan et al. observed that breast cancer patients who were physically active before diagnosis remained active post-diagnosis (Kwan et al. 2012). In addition, a majority (79.1\%) of our collective was already active before their disease. With respect to skin cancer, outdoor, PA is a risk factor for this type of cancer; therefore, people who practice outdoor activities are more likely suffering from skin cancer. Yet, the survey period took place through spring and summer as day length and weather conditions are known to influence PA which might lead to high reported PA (Wu et al. 2017). Regarding the tumor types in this survey skin and breast cancer, patients were highly represented, who often are younger. Ninety-three $\%$ of the participants were under 60 years. This most probably is also due to the online setting of the survey. In addition, they are treated with minor surgeries that might have a lower impact on strength and fitness and let to faster recovery. For further reasons, see "Limitations".

\section{Cancer patients showed high patient activation and self-efficacy}

Our collective showed comparable means for self-efficacy and patient activation to reference values [self-efficacy 3.7, reference value 4 (Constanze Beierlein et al. 2012); patient activation 71, reference value 67.5 (Zill et al. 2013)]. Although our patients showed high patient activation and self-efficacy, we could not prove them as predictors for PA. However, we could confirm our assumption that patient activation with small effect size and self-efficacy with middle effect size show negative correlations with disease burden. One explanation is that activated patients might have better coping strategies, because they know better about their disease and its consequences. Physicians should encourage these characteristics, keeping in mind that cancer diagnosis is an enormous burden for patients.

\section{Attitude towards PA}

Most cancer patients confirmed PA as an opportunity to cope with the disease and to reduce their cancer or recurrence risk and showed readiness for PA, which is similar to other examined cancer populations (Hoh et al. 2017; Smith et al. 2017). Moreover, only around one quarter was completely satisfied with their performed PA and most of the participants $(46.5 \%)$ wished to be more physically active. Yet, 25\% were at least partly worried that PA could harm them. Patients proclaimed that only "little information was given from oncology health professionals on how to achieve adequate levels of PA" (Smith et al. 2017) and only one in two patients reported to feel well informed about PA (Hoh et al. 2017). Patient education towards the positive effects of PA should be improved. Cancer patients should be aware that PA is feasible and harmless and provides significant health benefits. Regular offers, e.g., rehabilitation/cancer sports groups could help patients who can badly overcome to be physically active.

\section{Age is a predictor for PA}

Younger age increases the likeliness to engage in PA, which is in line with several studies (Bauman et al. 2012; Gerovasili et al. 2015). Although in the literature, there is evidence for relations between self-efficacy (Bauman et al. 2012; Coups et al. 2009), patient activation (McCabe et al. 2018), gender (Gerovasili et al. 2015; Loprinzi et al. 2013b; Smith et al. 2011), previous PA (Bauman et al. 2012) or therapy status (Hoh et al. 2017), and PA we could not confirm any of those as predictors for general PA nor for PA in leisure time. Moreover, the $R^{2}$ of the total PA regression model was only 0.103 , which means $90 \%$ of the variance of PA is explained by other factors than those included in our model. Predictors with more influence on PA might be education level, income, profession, obesity, general health status, genetics, family/friend support, living space (rural or urban) or environmental conditions such as access to sports facilities, further research should be done to show how PA can be predicted and influenced.

\section{Limitations}

The questionnaire was only addressed to members of online self-help groups. This might explain our extraordinary results in view of PA level and attitude towards PA. Considering that patients within online self-help groups might differ 
in their characteristics and show a different health awareness, e.g., are more likely to engage in self-management practices such as PA, are younger and might tend to have in general higher self-efficacy and patient activation scores. Moreover, it should be considered that patients with a greater affinity to PA were more motivated to answer a questionnaire towards PA or that patients answer more positively because of social desirability. Furthermore, it was a self-reported assessment, answers can be subjective and unreliable, in general, there is evidence that self-reported questionnaires tend to over-report PA in comparison to objective measures with accelerometer (Gaede-Illig et al. 2014). In addition, those with limited access or internet aversion are underrepresented in this study. In general, the relatively small sample size, the high level of PA and the not normally distributed MET-minutes/week in our study population might limit the generalizability of our results. We did not ask exactly what therapy the patients were undergoing; therefore, we cannot assess the impact of therapy on physical fitness. Furthermore, gender was unequally distributed and previous PA was only measured by one subjective dichotomous question. As well it was a short observation period and we did not ask for education level nor for socioeconomic status. We did not ask for participants' professions which limits the transparency of PA in the work domain.

\section{Conclusion}

In summary, it is important that all cancer patients, especially older ones, are encouraged to maintain their PA status and to help inactive survivors to increase their PA to benefit from the positive effects of PA. To avoid potential overestimation and make it easier to compare results objective measurement methods such as an accelerometer could be used. To examine a greater and more balanced population in future studies one possibility would be to offer online surveys on tablets in hospital or medical practice waiting areas. Another idea could be to generate a general mailing list for online surveys. Regarding the study design, questions should be easy to understand and time to completion should be short to increase the number of participants and their compliance. A concept to combine long-term research in PA and motivating cancer patients for PA would be to develop a smartphone app with an accelerometer to measure PA, reminder and instructions for practical exercises (photos, videos) to motivate patients and short questionnaires towards PA. Furthermore, more research should be conducted detecting relevant predictors for PA to detect patients at risk for low PA.

Acknowledgements Open Access funding provided by Projekt DEAL.
Author contributions All authors contributed to the study conception and design. Material preparation, data collection, and analysis were performed by IR. The first draft of the manuscript was written by IR. All authors commented on previous versions of the manuscript. All authors read and approved the final manuscript.

Funding There was no funding for this study.

Availability of data and material The data sets generated during and/or analysed during the current study are available from the corresponding author on reasonable request.

\section{Compliance with ethical standards}

Conflict of interest The authors declare no conflict of interest.

Ethical approval All procedures performed in studies involving human participants were in accordance with the ethical standards of the institutional and/or national research committee (ethic commission of the university hospital Jena 5483-03/18) and with the 1964 Helsinki declaration and its later amendments or comparable ethical standards.

Informed consent Informed consent was obtained from all individual participants included in the study.

Open Access This article is licensed under a Creative Commons Attribution 4.0 International License, which permits use, sharing, adaptation, distribution and reproduction in any medium or format, as long as you give appropriate credit to the original author(s) and the source, provide a link to the Creative Commons licence, and indicate if changes were made. The images or other third party material in this article are included in the article's Creative Commons licence, unless indicated otherwise in a credit line to the material. If material is not included in the article's Creative Commons licence and your intended use is not permitted by statutory regulation or exceeds the permitted use, you will need to obtain permission directly from the copyright holder. To view a copy of this licence, visit http://creativecommons.org/licenses/by/4.0/.

\section{References}

Bandura A (1994) Self-efficacy. Encycl Hum Behav 4:71-81

Bauman AE, Reis RS, Sallis JF, Wells JC, Loos RJF, Martin BW (2012) Correlates of physical activity: why are some people physically active and others not? Lancet 380:258-271. https:// doi.org/10.1016/S0140-6736(12)60735-1

Blanchard CM, Courneya KS, Stein K (2008) Cancer survivors' adherence to lifestyle behavior recommendations and associations with health-related quality of life: results from the American Cancer Society's SCS-II. J Clin Oncol 26:2198-2204. https://doi. org/10.1200/jco.2007.14.6217

Brenk-Franz K et al (2013) Validation of the German version of the patient activation measure 13 (PAM13-D) in an international multicentre study of primary care patients. PLoS One 8:e74786. https ://doi.org/10.1371/journal.pone.0074786

Committee IR (2005) Guidelines for data processing and analysis of the international physical activity questionnaire (IPAQ). http:// www.IPAQ.ki.se. Accessed 13 Dec 2018

Constanze Beierlein AK, Kemper CJ, Rammstedt B (2012) Ein Messinstrument zur Erfassung subjektiver Kompetenzerwartungen. https://www.gesis.org/angebot/publikationen/archiv/ gesis-working-papers/. Accessed 27 Nov 2018 
Coups EJ, Park BJ, Feinstein MB, Steingart RM, Egleston BL, Wilson DJ, Ostroff JS (2009) Correlates of physical activity among lung cancer survivors. Psycho-oncology 18:395-404. https:// doi.org/10.1002/pon. 1520

Craig CL et al (2003) International physical activity questionnaire: 12-country reliability and validity. Med Sci Sports Exerc 35:1381-1395. https://doi.org/10.1249/01.mss.0000078924 $.61453 . \mathrm{fb}$

Devoogdt N et al (2010) Physical activity levels after treatment for breast cancer: one-year follow-up. Breast Cancer Res Treat 123:417-425. https://doi.org/10.1007/s10549-010-0997-6

Ding Y, Huang L, Feng C, Yang M, Zhang Y (2017) Depression and self-efficacy in medical residents. J Cent South Univ Med Sci 42:83-87. https://doi.org/10.11817/j.i ssn.1672-7347.2017.01.014

Ferrer RA, Huedo-Medina TB, Johnson BT, Ryan S, Pescatello LS (2011) Exercise interventions for cancer survivors: a meta-analysis of quality of life outcomes. Ann Behav Med 41:32-47. https://doi.org/10.1007/s12160-010-9225-1

Friedenreich CM, Wang Q, Neilson HK, Kopciuk KA, McGregor SE, Courneya KS (2016) Physical activity and survival after prostate cancer. Eur Urol 70:576-585. https://doi.org/10.1016/j. eururo.2015.12.032

Froböse I, Wallmann-Sperlich B (2018) Der DKV-Report 2018 Wie gesund lebt Deutschland? https://www.dkv.com/downl oads/20150126-DKV-Report-2015-Wie-gesund-lebt-Deutschlan d.pdf. Accessed 10 Dec 2018

Gaede-Illig C, Alfermann D, Zachariae S, Menzel C (2014) Körperliche Aktivität erfassen-ein Vergleich vom IPAQ-SF und dem SenseWear Pro Armband. Deutsche Zeitschrift für Sportmedizin. https://doi.org/10.5960/dzsm.2014.130

Gerovasili V, Agaku IT, Vardavas CI, Filippidis FT (2015) Levels of physical activity among adults 18-64 years old in 28 European countries. Prev Med 81:87-91. https://doi.org/10.1016/j.ypmed .2015 .08 .005

Goodworth M-CR, Stepleman L, Hibbard J, Johns L, Wright D, Hughes MD, Williams MJ (2014) Variables associated with patient activation in persons with multiple sclerosis. J Health Psychol 21:82-92. https://doi.org/10.1177/1359105314522085

Hayes SC et al (2013) Exercise for health: a randomized, controlled trial evaluating the impact of a pragmatic, translational exercise intervention on the quality of life, function and treatment-related side effects following breast cancer. Breast Cancer Res Treat 137:175-186. https://doi.org/10.1007/s10549-012-2331-y

Hibbard JH, Mahoney ER, Stock R, Tusler M (2007) Do increases in patient activation result in improved self-management behaviors? Health Serv Res 42:1443-1463. https://doi.org/10.111 1/j.1475-6773.2006.00669.x

Hibbard JH, Mahoney E, Sonet E (2017) Does patient activation level affect the cancer patient journey? Patient Educ Couns 100:12761279. https://doi.org/10.1016/j.pec.2017.03.019

Hoh JC, Schmidt T, Hubner J (2017) Physical activity among cancer survivors-what is their perception and experience? Support Care Cancer. https://doi.org/10.1007/s00520-017-3977-0

Irwin ML et al (2003) Physical activity levels before and after a diagnosis of breast carcinoma: the Health, Eating, Activity, and Lifestyle (HEAL) study. Cancer 97:1746-1757. https://doi.org/10.1002/ cncr. 11227

Jessica Greene JHH, Sacks Rebecca, Overton Valerie, Parrotta Carmen D (2015) When patient activation levels change, health outcomes and costs change, too. Health Aff 34:431-437. https://doi. org/10.1377/hlthaff.2014.0452

Kenfield SA, Stampfer MJ, Giovannucci E, Chan JM (2011) Physical activity and survival after prostate cancer diagnosis in the health professionals follow-up study. J Clin Oncol 29:726-732. https:// doi.org/10.1200/jco.2010.31.5226
Kwan ML et al (2012) Change in physical activity during active treatment in a prospective study of breast cancer survivors. Breast Cancer Res Treat 131:679-690. https://doi.org/10.1007/s1054 9-011-1788-4

Lear SA, Hu W, Rangarajan S, Gasevic D, Leong D, Iqbal R et al (2017) The effect of physical activity on mortality and cardiovascular disease in 130,000 people from 17 high-income, middle-income, and low-income countries: the PURE study. Lancet 390:2643-2654. https://doi.org/10.1016/s0140-6736(17)31634-3

Loprinzi P, Lee H, Cardinal B (2013a) Objectively measured physical activity among US cancer survivors: considerations by weight status. J Cancer Surviv Res Pract. https://doi.org/10.1007/s1176 4-013-0293-7

Loprinzi PD, Lee H, Cardinal BJ (2013b) Objectively measured physical activity among US cancer survivors: considerations by weight status. J Cancer Surviv 7:493-499. https://doi.org/10.1007/s1176 4-013-0293-7

McCabe PJ, Stuart-Mullen LG, McLeod CJ, O Byrne T, Schmidt MM, Branda ME, Griffin JM (2018) Patient activation for self-management is associated with health status in patients with atrial fibrillation. Patient Prefer Adher 12:1907-1916. https://doi.org/10.2147/ PPA.S172970

McNeely ML, Campbell KL, Rowe BH, Klassen TP, Mackey JR, Courneya KS (2006) Effects of exercise on breast cancer patients and survivors: a systematic review and meta-analysis. CMAJ 175:3441. https://doi.org/10.1503/cmaj.051073

McTiernan A (2008) Mechanisms linking physical activity with cancer. Nat Rev Cancer 8:205-211. https://doi.org/10.1038/nrc2325

Nelson SH et al (2016) Impact of very low physical activity, BMI, and comorbidities on mortality among breast cancer survivors. Breast Cancer Res Treat 155:551-557. https://doi.org/10.1007/ s10549-016-3694-2

Rock CL et al (2012) Nutrition and physical activity guidelines for cancer survivors. CA Cancer J Clin 62:243-274. https://doi. org/10.3322/caac. 21142

Schmid D, Leitzmann MF (2014) Association between physical activity and mortality among breast cancer and colorectal cancer survivors: a systematic review and meta-analysis. Ann Oncol 25:12931311. https://doi.org/10.1093/annonc/mdu012

Smith WA, Nolan VG, Robison LL, Hudson MM, Ness KK (2011) Physical activity among cancer survivors and those with no history of cancer-a report from the National Health and Nutrition Examination Survey 2003-2006. Am J Transl Res 3:342-350

Smith L, Croker H, Fisher A, Williams K, Wardle J, Beeken RJ (2017) Cancer survivors' attitudes towards and knowledge of physical activity, sources of information, and barriers and facilitators of engagement: a qualitative study. Eur J Cancer Care 26:e12641. https://doi.org/10.1111/ecc.12641

van Zutphen $\mathrm{M}$ et al (2017) An increase in physical activity after colorectal cancer surgery is associated with improved recovery of physical functioning: a prospective cohort study. BMC Cancer 17:74. https://doi.org/10.1186/s12885-017-3066-2

Wu Y-T, Luben R, Wareham N, Griffin S, Jones AP (2017) Weather, day length and physical activity in older adults: cross-sectional results from the European Prospective Investigation into Cancer and Nutrition (EPIC) Norfolk Cohort. PLoS One 12:e0177767e0177767. https://doi.org/10.1371/journal.pone.0177767

Zill JM, Dwinger S, Kriston L, Rohenkohl A, Härter M, Dirmaier J (2013) Psychometric evaluation of the German version of the patient activation measure (PAM13). BMC Public Health 13:1027. https://doi.org/10.1186/1471-2458-13-1027

Publisher's Note Springer Nature remains neutral with regard to jurisdictional claims in published maps and institutional affiliations. 